\title{
Effects of mechanical injury and insect feeding on volatiles emitted by wheat plants
}

\author{
Dariusz Piesik, Anna Wenda-Piesik, Robert Lamparski, Piotr Tabaka, Tomasz Ligor \\ \& Bogusław Buszewski
}

Piesik, D., Wenda-Piesik, A., Lamparski, R., Tabaka, P., Ligor. T. \& Buszewski, B. 2010: Effects of mechanical injury and insect feeding on volatiles emitted by wheat plants. — Entomol. Fennica 21: 117-128.

We report on changes in the volatiles emitted by wheat plants of the cultivar 'Tonacja' after the plants were scraped, pierced or damaged by adults of Oulema melanopus (Linnaeus). The blend of volatiles was dominated by typical green leaf volatiles and in addition contained linalool and B-caryophyllene, but the latter two were released in large amounts only after more than one day of insect feeding. Overall, the plants that had been damaged by the insect released more odors than the plants that were subjected to mechanical damage. Moreover, control plants released significantly lower amounts of volatiles. Scraping of leaves induced higher volatile emission than puncturing the leaves. A Y-tube bioassay was used to evaluate upwind orientation of adult cereal leaf beetles. Greater number of female $O$. melanopus was attracted to (Z)-3-hexenal and (Z)-3-hexenyl acetate at low concentrations. Higher concentration of these compounds and linalool significantly repelled both females and males.

D. Piesik \& R. Lamparski, University of Technology and Life Sciences, Department of Applied Entomology, 85 - 225 Bydgoszcz, 20 Kordeckiego St., Poland; E-mail of the corresponding author: piesik@utp.edu.pl

A. Wenda-Piesik, University of Technology and Life Sciences, Department of Plant Growth Principles and Experimental Methodology, 85 - 225 Bydgoszcz,

20 Kordeckiego St., Poland; E-mail: apiesik@utp.edu.pl

P. Tabaka, Forest Department Zoledowo, 86-031 Osielsko, 4a Parkowa St., Poland; E-mail: piotr.tabaka@torun.lasy.gov.pl

T. Ligor \& B. Buszewski, Nicolaus Copernicus University, Faculty of Chemistry, Chair of Environmental Chemistry and Bioanalytics, 87-100 Toruń, 7 Gagarina St., Poland; E-mail for B. Buszewski: bbusz@chem.uni.torun.pl

Received 25 September 2009, accepted 5 February 2010

\section{Introduction}

Plants are often attacked by many herbivorous insects and pathogens at the same time (Thaler et al. 2002). However, plants are not merely passive victims of attacking herbivores. They have evolved an arsenal of physical and chemical de- fenses to protect themselves (Rasmann et al. 2005).

It is well known that some plants respond to mechanical injury by deploying various biochemical defense mechanisms (Karban \& Baldwin 1997). It was also previously documented that emissions of volatile organic compounds 
(VOC) from injured plants may attract herbivores and their parasitoids (De Moraes et al. 2001, Cardoza et al. 2003).

Plants attacked by pathogenic fungi can also evolve chemical defense mechanisms (Karban \& Baldwin 1997, Agrawal et al. 1999, Cardoza et al. 2002, Cardoza et al. 2003, Vikram et al. 2005). The essential oils can be active against the fungal pathogens and cause significantly reduced fungal hyphal growth compared with the control (Alvarez-Castellanos et al. 2001). Plants infected by Fusarium spp. can emit volatile chemicals that differ both quantitatively and qualitatively from undamaged plants (Piesik et al. 2007).

Defense system of plants can be enhanced by chemical signals, which are released in consequence of insect feeding (Karban 1985, Turlings et al. 1990, McCall et al. 1993). Cereal leaf beetle, Oulema melanopus (Linnaeus) represents the most important pest of wheat in many countries (Dimitrijevic et al. 1999). Two species of leaf beetle, O. melanopus and O. gallaeciana Heyden, are classified as pests of cereals of economic importance in Poland (Walczak 2005a,b). These insects are well spread over the world. There are reports about the ear weight losses caused by larvae of $O$. melanopus from Russia (Sokolov 1999), Austria (Meindl et al. 2001), Turkey (Bayram et al. 2004), Romania (Popov et al. 2005), and the USA (Buntin et al. 2004, Olfert et al. 2004).

The knowledge of the blend of volatiles that wheat produces may be useful in understanding the plant-insect relation (Buttery et al. 1985). Manipulating volatile signals may help increase the effectiveness of the natural enemies as control agents (Dicke \& Sabelis 1988, De Moraes et al. 1998, Turlings et al. 1990, Thaler 1999, Kessler \& Baldwin 2001, Reddy \& Guerrero 2004).

In the present study, we identified volatiles produced by a cultivar of wheat commonly grown in Poland. The volatiles were collected from plants during stem elongation, the predominant stage at which plants are susceptible to infestation by cereal leaf beetles in the field due to the synchrony between adult flight and crop phenology. The purpose of the current research was to assess the effect of two types of mechanical injuries and feeding of cereal leaf beetles on volatile production by winter wheat cv. 'Tonacja'. We also conducted behavioral experiments to test the response of cereal leaf beetles to green leaf volatiles (GLV) to identify potential attractants or repellents.

\section{Materials and methods}

\subsection{Plant culture}

Winter wheat cv. 'Tonacja' was used in the experiments conducted in a greenhouse. The plants were separated for the experiments testing the effects of the type of mechanical injury and insect feeding. One hundred and four plants were grown two per pot in sterilized soil, but only fifty two plants, each in separate pot, were randomly chosen for further experiment.

The experiments were performed at the Plant Growth Center (University of Technology and Life Sciences, Bydgoszcz, Poland) in 2007 and 2008. The plants were grown under supplemental light and ambient humidity. The photoperiod was 16L: 8D. Daytime temperature was $22 \pm 2{ }^{\circ} \mathrm{C}$ and the overnight temperature was $18 \pm 2{ }^{\circ} \mathrm{C}$. The plants were watered four times weekly, and fertilized with Peters ${ }^{\circledR}$ General Purpose Fertilizer (J.R. Peters Inc., Allentown, Pennsylvania, U.S.A.) at $100 \mathrm{ppm}$ in aqueous solution twice each week as part of the regular watering schedule. Fertilizing commenced when the plants reached the third leaf stage.

\subsection{Mechanical wounding}

The plants were wounded immediately before the experiment. The main stem from each plant was subjected to wounding. All plants used were at the Zadoks 32 stage (cereal development scale (from 10 to 92) proposed by the Dutch phytopathologist Jan C. Zadoks that is widely used in cereal research and agriculture), with the emergence of an elongating stem section separating the first two nodes (Zadoks et al. 1974). Furthermore, disease control is most critical in the stem extension and heading stage $(31,32,35)$. At this stage, there are five large leaves projecting upwards from the area of the elongating stem in addition to numerous more mature leaves lower 
on the plant and on the tillers. Two types of injury were performed on the plants. This was used to simulate feeding damage of insects. These were:

1. Scraped Leaf $(\mathrm{S})$ : all leaves of the main stem were abraded by a single rasp with a large bore needle (diameter $1.64 \mathrm{~mm}$, length 3.3 $\mathrm{cm}$,

2. Pierced Leaf $(\mathrm{P})$ : all leaves of the main stem were punctured by a small-bore needle (diameter $0.34 \mathrm{~mm}$ ). Five holes were made in each leaf.

\subsection{Infestation by cereal leaf beetles}

The main stem from every pot was put in plastic cylinder. On the top and bottom of the plastic cylinder (9 $\mathrm{cm}$ long, $4.5 \mathrm{~cm}$ diameter), two holes were made to surround the inserted wheat stem. One pair of newly-emerged beetles of $O$. melanopus (females and males, recognized by ' in copula' phase) were introduced in each cylinder. The plants were subjected to feeding for $24 \mathrm{~h}$.

\subsection{Volatile Collection System (VCS)}

Volatiles were collected simultaneously from Nalophan (odor and taste-free cooking bags made of a plastic film resistant in the temperature range from $-60^{\circ} \mathrm{C}$ to $+220^{\circ} \mathrm{C}$ ) enclosed 'Tonacja' wheat plants. The apparatus allowed the collection of odors from 4 plants at the same time. The plants were subjected to collection in a random order. A volatile collector trap (glass tube, length $76 \mathrm{~mm}$, outside diameter $6.35 \mathrm{~mm}$; Analytical Research Systems, Inc., Gainesville, Florida, USA) containing $30 \mathrm{mg}$ of Super-Q (Alltech Associates, Inc., Deerfield, Illinois, USA) adsorbent was inserted into each of 4 Tygon tubes (connection between airflow meter and collector trap). Purified and humidified air was delivered at a rate of $1.01 \cdot \mathrm{min}^{-1}$ over the plants, and a vacuum pump sucked $20 \%$ less $\left(0.81 \cdot \mathrm{min}^{-1}\right)$ to avoid collecting odors from any gap of the system.

Volatiles were collected from the main stem, while the tillers were outside volatile collection chamber. The volatile collection sequence (threehr collections) was initiated on Zadoks 32. Three experiments in three consecutive days on the same plants (Day first - I, Day second - II, Day third - III) were done: 20 plants for mechanical injury (10 for scraped and 10 for pierced leaves) plus 6 controls, 20 plants (treatments) for 1 pair of beetles and 6 controls. Additionally 2 blanks (odors collected from empty Nalophan bags only) were checked.

\subsection{Y-tube experiment}

There were three compounds that were chosen for Y-tube experiments; two GLV ((Z)-3-hexenal and (Z)-3-hexenyl acetate), and linalool (terpene). For those volatiles the highest emissions in consequence of feeding by cereal leaf beetles were observed.

The Y-tube system used was similar to that described by Piesik et al. (2008). A charcoal-purified and humidified air stream was connected to each arm of the Y-tube by a threaded 24/410 (inner diameter $24 \mathrm{~mm}$ ) cap with a Teflon liner coupled to a $0.64-\mathrm{cm}$ Swagelock union delivering air via Teflon tubing (outer diameter $0.64 \mathrm{~cm}$ ). The airflow was set at $0.8 \mathrm{l} / \mathrm{min}$ using a flowmeter. The synthetic or plant test stimulus was placed in either a synthetic lure (outer diameter $24 \mathrm{~mm}$, length $8 \mathrm{~cm}$ ) or a Corning tube (outer diameter 24 $\mathrm{mm}$, length $46 \mathrm{~cm})$. The Y-tube olfactometer comprised Corning glass tubing (outer diameter $28 \mathrm{~mm}$, length $30 \mathrm{~cm}$ ) that branched at $20 \mathrm{~cm}$. The interior angle of the ' $\mathrm{Y}$ ' was $120^{\circ}$, and the diverging arms extended for $4 \mathrm{~cm}$ in each direction before becoming parallel for their final $10 \mathrm{~cm}$, and then terminated in a female ground-glass joint at the end of each arm.

The male ground glass joint on the stimulusdelivery tube was inserted into the receiving arm of the Y-tube, yielding a consistent airtight fit. Bioassay subjects were placed in the unbranched section of the $\mathrm{Y}$-tube at approximately $2 \mathrm{~cm}$ from the outlet. A $6.3 \mathrm{~V}$ bulb (lamp type 46; Radio Shack, Fort Worth, Texas) was placed between the apexes of the Y-tube arms; equality in illumination supplied to the two arms was verified using a pyranometer (model LI-200SA; LI-COR, Inc., Lincoln, Nebraska).

To screen behavioral activity of the volatile compounds identified from wheat plants, com- 


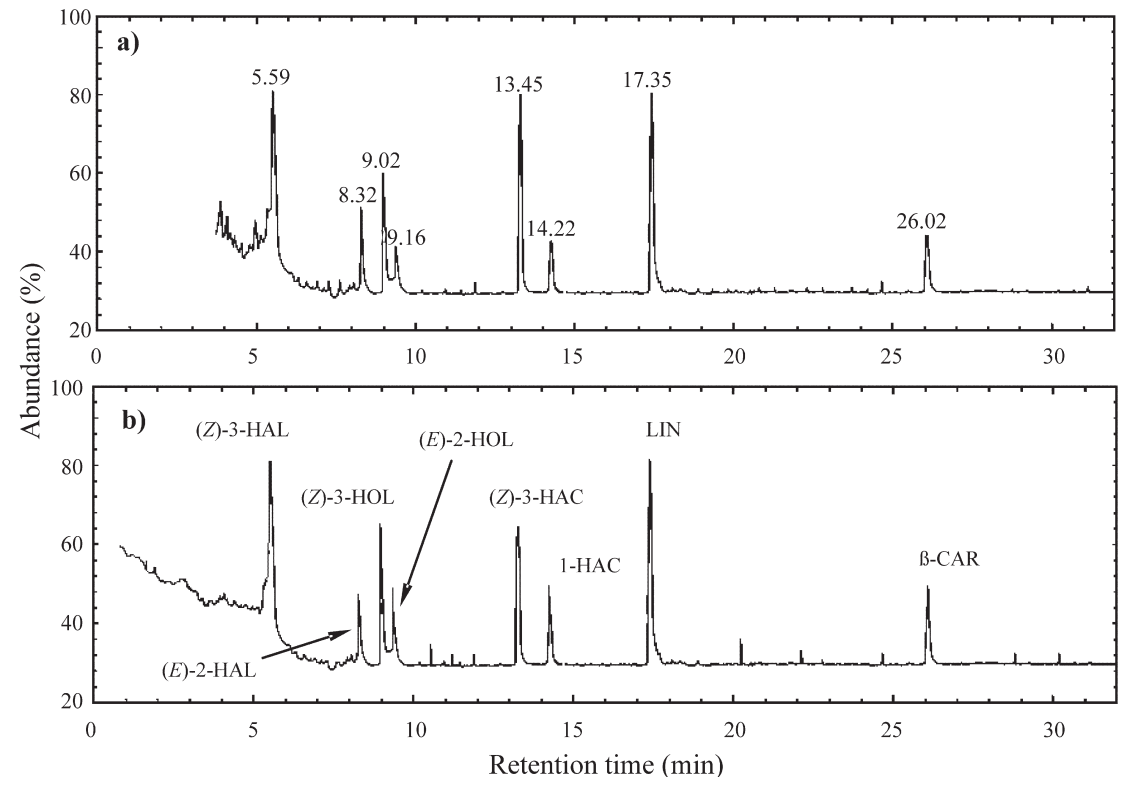

Fig. 1. Coupled gas chromatographymass spectrometry diagrams. - a. Standard mixture containing volatile organic compounds with their extract retention times above each peak. - b. An example of collected volatiles, named above each peak. mercially available compounds (Sigma-Aldrich Chemical Co. Inc.) were used at four concentrations (the range of concentrations used in the bioassays - mean of first, second, third collection day and control/healthy plants; see Table 2). For the behavior experiment we recalculated $\mathrm{ng} \cdot \mathrm{h}^{-1}$ to $n g \cdot \min ^{-1}$ (insects walked inside the Y-tube through minutes not hours). All tested compounds (within one component, from the smallest to the highest concentration) were put on one quarter (circle $\check{\mathrm{R}} 70 \mathrm{~mm}$ cut in four pieces) of filter paper $(50 \mu \mathrm{l})$ folded inside a microcentrifuge tube. Manipulation of the rates of synthetic volatiles were performed by varying the concentration of terpene solution and by varying the number of holes in the cap. Suitable releasing was previously checked by VCS and GC-MS. The microcentrifuge cap was left open for $1 \mathrm{~min}$ to allow the evaporation of the first strong signal of hexane and tested compound.

Insects were observed for $5 \mathrm{~min}$, or until they have chosen one of the arms of the Y-tube. Thirty insects of each sex were used for each concentration of all tested compounds. All bioassays were conducted with newly-emerged adults (females and males).

Statistical analyses were performed using a chi-square test for small sample sizes (Sokal \& Rohlf 1995).

\subsection{Analytical methods}

Volatiles were eluted from the Super-Q collection trap with $225 \mu \mathrm{l}$ of hexane containing $7 \mathrm{ng}$ of decane as an internal standard. Volatiles were analyzed by coupled gas chromatography-mass spectrometry (GC-MS). The compounds were ordered on the chromatogram by their retention time (from 5.59 min to $26.02 \mathrm{~min}$; Fig. 1a). The GC Perkin Elmer AutoSystem XL fitted with a 30-m DB-5MS capillary column (0.25-mm-ID, $0.25 \mu \mathrm{m}$ film thickness; Restek, USA). The temperature program increased the chromatography oven temperature from $40{ }^{\circ} \mathrm{C}$ to $200{ }^{\circ} \mathrm{C}$ at $5^{\circ} \mathrm{C} \cdot \mathrm{min}^{-1}$. The identification of volatiles was verified with authentic standards that had the same GC retention times and mass spectra. Peaks were integrated directly from the GC-chromatogram. The amount of each compound (x) was calculated according to the following equation $\left(\mathrm{ng} \cdot \mathrm{h}^{-1}\right)$ :

$\mathrm{x}=\mathrm{S}_{\text {compound }} \times \mathrm{ISTD} / \mathrm{S}_{\text {istd }}$

where $\mathrm{S}_{\text {compound }}=$ the area of the compound, ISTD = internal standard, $7 \mathrm{ng}$, and $\mathrm{S}_{\mathrm{ISTD}}=$ area of the internal standard. 
(Z)-3-HAL a

${ }^{1} \mathrm{~F}(2 ; 57)=779.5 \mathrm{p}<0.001$

${ }^{2} \mathrm{~F}(2 ; 15)=0.55 \mathrm{p}=0.59$

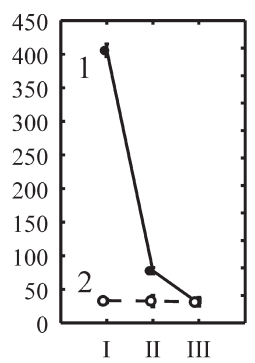

(Z)-3-HAC $\mathrm{e}$

${ }^{1} \mathrm{~F}(2 ; 57)=2714.5 \mathrm{p}<0.001$

${ }^{2} \mathrm{~F}(2 ; 15)=0.23 \mathrm{p}=0.79$

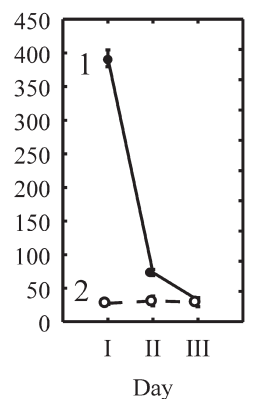

(E)-2-HAL

$\mathrm{F}(2 ; 57)=113.4 \mathrm{p}<0.001$

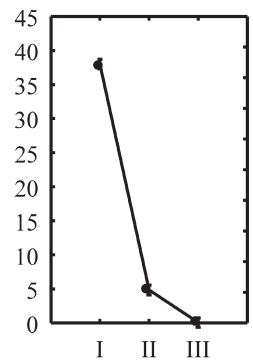

1-HAC f

$\mathrm{F}(2 ; 57)=270.5 \mathrm{p}<0.001$

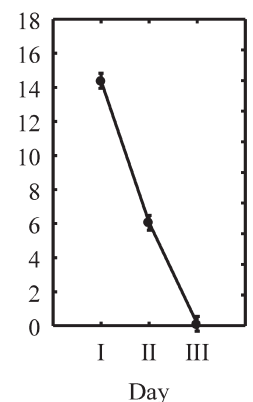

(Z)-3-HOL c

${ }^{1} \mathrm{~F}(2 ; 57)=637.4 \mathrm{p}<0.001$

${ }^{2} \mathrm{~F}(2 ; 15)=0.16 \mathrm{p}=0.86$

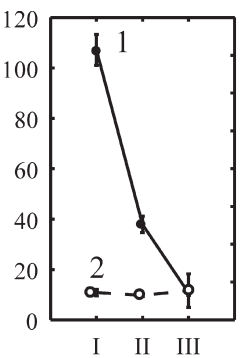

LIN

$\mathrm{F}(2 ; 57)=53.2 \mathrm{p}<0.001$

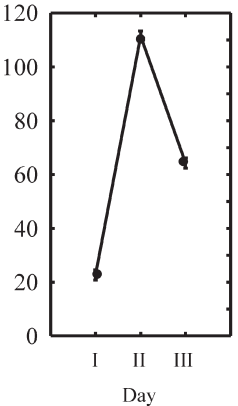

(E)-2-HOL

$F(2 ; 57)=329.9 p<0.001$

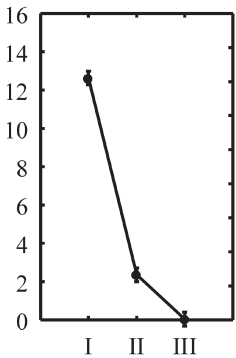

$\beta$-CAR h

$\mathrm{F}(2 ; 57)=156.2 \mathrm{p}<0.001$

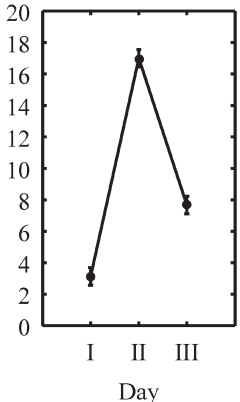

Fig. 2. Release of volatile organic compounds (means $\pm S$. E. in $n g \cdot h^{-1}$ ) by winter wheat cv. 'Tonacja' after 1-3 days of Oulema melanopus feeding (solid line) and control/uninfected plants (dashed line). For figures without control lines, the amounts of compounds in controls were very low (see Section 3.1.1.) and are not shown.

\subsection{Statistical analyses}

The experimental design was completely random for two experiments. One-way analysis of variance was performed on the data of each volatile compound released after $O$. melanopus injury. The times (three days) of collection of the compounds after injury were the levels of the factor. Twenty plants exposed to the $O$. melanopus feeding and six control (uninfected) plants were considered as replicates.

Two-way analysis of variance was used for the data in the $2^{\text {nd }}$ experiment, where the factors were the way of mechanical injury and the time of compound collection. In this experiment, ten plants were considered as replicates. There were also six control (undamaged) plants.

One-way ANOVA was used to test the effect of time of compound collection on the amounts released by control plants in both experiments.

The means were separated using a Tukey's honestly significant difference (HSD) test ( $\alpha=$ 0.05 ). The analyses were processed by Statistica 8.0 program.

\section{Results}

\subsection{Volatiles after foliar damage}

We identified in our experiments 8 odor compounds released by winter wheat cv. 'Tonacja' in consequence of biotic and abiotic stress. Of these six were green leaf volatiles (GLV): (Z)-3hexenal $=(Z)$-3-HAL, $(E)$-2-hexenal $=(E)$-2HAL, (Z)-3-hexen-1-ol = (Z)-3-HOL, $(E)$-2hexen-1-ol = (E)-2-HOL, $(Z)$-3-hexen-1-yl acetale $=(Z)-3-$ HAC, 1 -hexyl acetale $=1$-HAC. In addition, two terpenoids were identified, linalool $=$ LIN (entantiomers R or S not identified) and $\beta$-caryophyllene $=\beta$-CAR. Chromatograms of VOC standard and represen- 
(Z)-3-HAL a

${ }^{1} \mathrm{~F}(2 ; 54)=261.6 \mathrm{p}<0.001$

${ }^{2} \mathrm{~F}(2 ; 15)=0.54 \mathrm{p}=0.59$

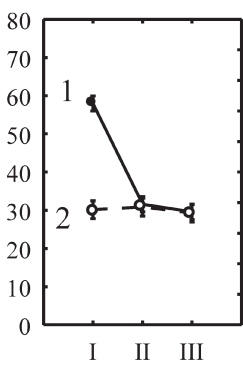

(Z)-3-HAC

${ }^{1} \mathrm{~F}(2 ; 54)=133.5 \mathrm{p}<0.001$

${ }^{2} \mathrm{~F}(2 ; 15)=0.29 \mathrm{p}=0.75$

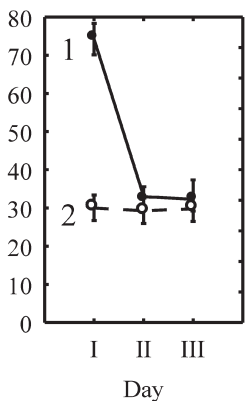

(E)-2-HAL b

$\mathrm{F}(2 ; 54)=522.2 \mathrm{p}<0.001$

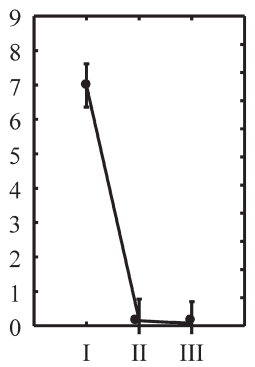

1-HAC f

$\mathrm{F}(2 ; 54)=131.5 \mathrm{p}<0.001$

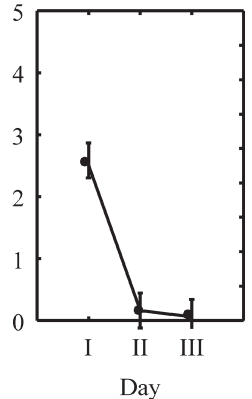

(Z)-3-HOL c

${ }^{1} \mathrm{~F}(2 ; 54)=379.9 \mathrm{p}<0.001$

${ }^{2} \mathrm{~F}(2 ; 15)=0.68 \mathrm{p}=0.52$

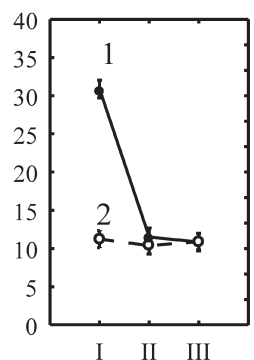

LIN g

$\mathrm{F}(2 ; 54)=0.52 \mathrm{p}=0.40$

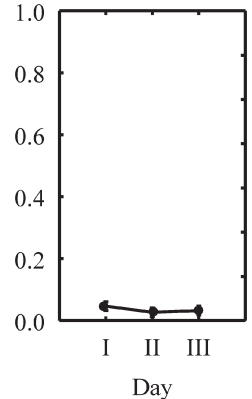

(E)-2-HOL d

$\mathrm{F}(2 ; 54)=152.9 \mathrm{p}<0.001$

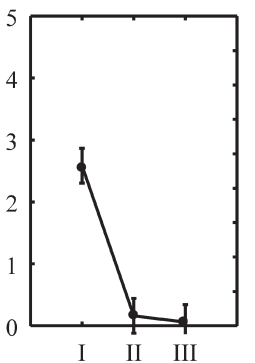

$\beta$-CAR h $\mathrm{F}(2 ; 54)=0.24 \mathrm{p}=0.79$

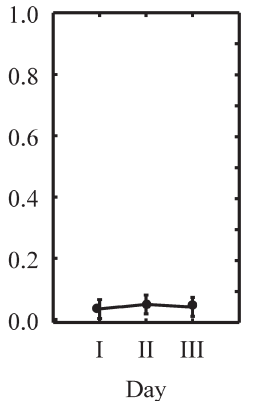

Fig. 3. Release of volatile organic compounds (means $\pm S$. $E$ in $n g \cdot h^{-1}$ ) by winter wheat cv. 'Tonacja' after 1-3 days of mechanical injury (means of scraped and pierced treatments) (solid line) and control/undamaged plants (dashed line). For the Time after injury $\times$ Type of injury interaction, see Fig. 4 . For figures without control lines, the amounts of compounds in controls were very low (see Section 3.1.3.) and are not shown.

tative sample are presented in Figs. 1a, b. All these compounds are separated during a $30 \mathrm{~min}$ chromatographic run.

\subsubsection{Volatiles after insect-caused foliar damage}

Wheat plants infested by $O$. melanopus released significantly higher amounts of volatile compounds relative to the control. The control plants produced constant amounts of volatiles within 3 days (means of three days): LIN: $0.01 \mathrm{ng} \cdot \mathrm{h}^{-1}$, $\mathrm{F}(2 ; 15)=3.55 ; \beta$-CAR: $0.03 \mathrm{ng} \cdot \mathrm{h}^{-1}, \mathrm{~F}(2 ; 15)=$ $0.68 ;(E)-2$-HAL: $0.07 \mathrm{ng} \cdot \mathrm{h}^{-1}, \mathrm{~F}(2 ; 15)=0.54$; (E)-2-HOL: $0.03 \mathrm{ng} \cdot \mathrm{h}^{-1}, \mathrm{~F}(2 ; 15)=0.02$; (Z)-3HAC: $29.34 \mathrm{ng} \cdot \mathrm{h}^{-1}, \mathrm{~F}(2 ; 15)=0.23$; $(Z)-3$-HAL: $32.51 \mathrm{ng} \cdot \mathrm{h}^{-1}, \mathrm{~F}(2 ; 15)=0.55 ; 1-\mathrm{HAC}: 0.04 \mathrm{ng} \cdot \mathrm{h}^{-1}$, $\mathrm{F}(2 ; 15)=0.95 ;(Z)-3-\mathrm{HOL}: 10.77 \mathrm{ng} \cdot \mathrm{h}^{-1}, \mathrm{~F}(2 ; 15)$ $=0.16$ (see also Fig. 2).

The highest amount of volatiles was observed for $(Z)-3-H A L$ in consequence of feeding by cereal leaf beetles (Fig. 2a). After $24 \mathrm{~h}$ of insect feeding (Day I) we recorded over $400 \mathrm{ng} \cdot \mathrm{h}^{-1} \mathrm{re}-$ leased by damaged wheat plants (Fig. 2a). (Z)-3HAC was also emitted in similar amounts after feeding by adults of $O$. melanopus. For each GLV, the largest released amount was noted on the first day of collection (Figs. 2a-f). Amounts of LIN and $\beta-C A R$ increased after insect feeding (Figs. 2g, h). Blank trials (empty Nalophan bags) did not show any volatiles on the chromatograms.

\subsubsection{Volatiles after mechanical foliar damage}

(Z)-3-HAC and (Z)-3-HAL were the compounds collected in the greatest amounts (Table 1) from both scraped and pierced plants (Table 1). The trend for ( $Z$ )-3-HAC production was also similar to that of (Z)-3-HAL (Fig. 3). Generally, pierced type of mechanical injury induced wheat plants to 
Table 1.Volatile organic compounds released $(\mathrm{ng} \cdot \mathrm{h}-1)$ by mechanically injured winter wheat cv. 'Tonacja', df1=1, df2=54 for all $F$-values.

\begin{tabular}{|c|c|c|c|c|}
\hline Injury & $\begin{array}{l}\text { LIN } \\
\text { Mean } \pm S . E .\end{array}$ & $\begin{array}{l}\beta \text {-CAR } \\
\text { Mean } \pm S . E .\end{array}$ & $\begin{array}{l}\text { (E)-2-HAL } \\
\text { Mean } \pm S . E .\end{array}$ & $\begin{array}{l}(\mathrm{E})-2-\mathrm{HOL} \\
\text { Mean } \pm S . E .\end{array}$ \\
\hline Scraped & $0.04 \pm 0.01$ & $0.05 \pm 0.01$ & $3.97 \pm 1.01$ & $1.62 \pm 0.40$ \\
\hline \multirow[t]{3}{*}{ Pierced } & $0.04 \pm 0.01$ & $0.03 \pm 0.01$ & $0.85 \pm 0.21$ & $0.25 \pm 0.06$ \\
\hline & $F=0.003$ & $F=1.32$ & $F=226.6$ & $F=104.7$ \\
\hline & $p=0.95$ & $p=0.27$ & $p<0.001$ & $p<0.001$ \\
\hline \multirow[t]{2}{*}{ Injury } & (Z)-3-HAC & (Z)-3-HAL & 1-HAC & (Z)-3-HOL \\
\hline & Mean $\pm S . E$. & Mean $\pm S . E$. & Mean $\pm S . E$. & Mean $\pm S . E$. \\
\hline Scraped & $54.95 \pm 5.74$ & $45.17 \pm 3.66$ & $1.57 \pm 0.39$ & $20.38 \pm 2.45$ \\
\hline \multirow[t]{3}{*}{ Pierced } & $38.84 \pm 2.04$ & $34.25 \pm 1.49$ & $0.25 \pm 0.08$ & $15.12 \pm 1.11$ \\
\hline & $F=46.5$ & $F=93.2$ & $F=88.9$ & $F=60.8$ \\
\hline & $p<0.001$ & $p<0.001$ & $p<0.001$ & $p<0.001$ \\
\hline
\end{tabular}

release significantly lower amount of semiochemicals (Table 1).

The variation in the amounts of $(E)-2-\mathrm{HAL}$,
(E)-2-HOL, (Z)-3-HAC, (Z)-3-HAL, 1-HAC, and $(Z)-3-\mathrm{HOL}$ were also significantly explained by the post-injury interval (Days I, II, III) (Fig. 3).
(Z)-3-HAL a

$\mathrm{F}(2 ; 54)=65.5 \mathrm{p}<0.001$

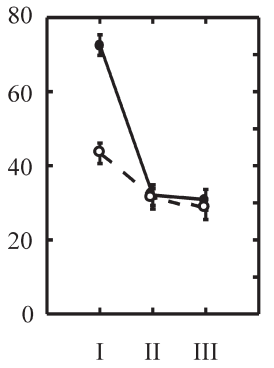

(Z)-3-HAC e

$\mathrm{F}(2 ; 54)=32.4 \mathrm{p}<0.001$

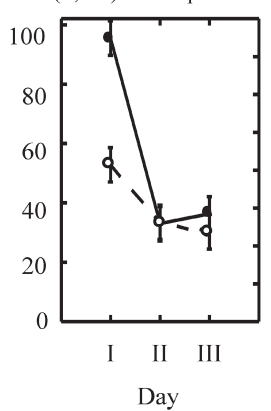

(E)-2-HAL b

$\mathrm{F}(2 ; 54)=226.6 \mathrm{p}<0.001$

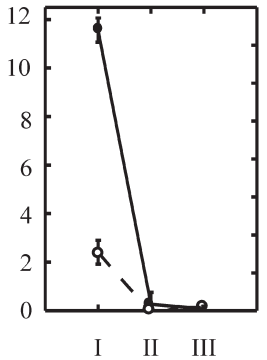

1-HAC f

$\mathrm{F}(2 ; 54)=73.5 \mathrm{p}<0.001$

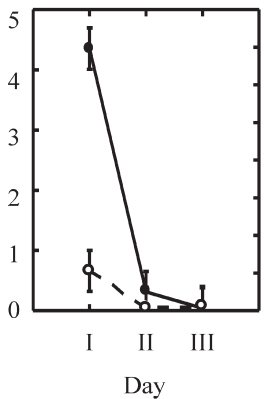

(Z)-3-HOL c

$\mathrm{F}(2 ; 54)=56.3 \mathrm{p}<0.001$

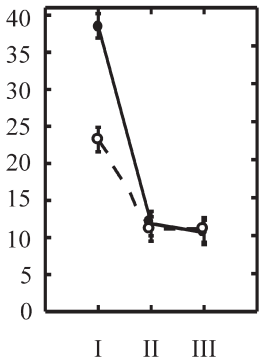

LIN g

$\mathrm{F}(2 ; 54)=0.04 \mathrm{p}=0.96$

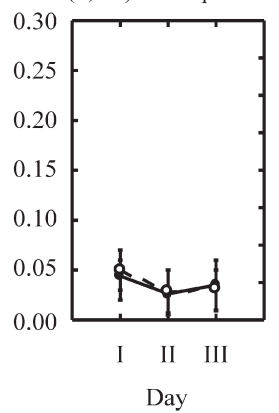

(E)-2-HOL

$\mathrm{F}(2 ; 54)=90.4 \mathrm{p}<0.001$

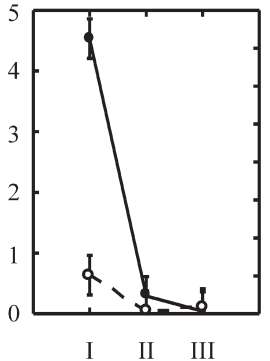

B-CAR h

$\mathrm{F}(2 ; 54)=0.38 \mathrm{p}=0.69$

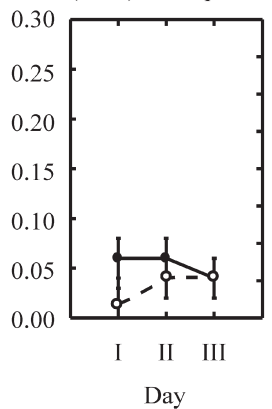

Fig. 4. Release of volatile organic compounds (means $\pm S . E$ in $n g \cdot h^{-1}$ ) by mechanically injured winter wheat $\mathrm{cv}$. 'Tonacja'. ANOVA results for Time after injury $\times$ Type of injury (scraped - solid line, pierced - dashed line) are presented. 
The overall amount of GLV produced across injury types was significantly greater immediately after injury (Day I) and at two days after injury (Day II) than for three days after injury (Day III). Some other general comparisons for GLV production were apparent from these experiments. (Z)-3-HAC release was clearly highest across the collection days on the first day after injury, peaking at a mean of $74.22 \mathrm{ng} \cdot \mathrm{h}^{-1}$ (Fig. 3e). The smallest amounts were recorded for 1-HAC, $(E)$-2HOL, and (E)-2-HAL (mean $0.05 \mathrm{ng} \cdot \mathrm{h}^{-1}, 0.06$ $\mathrm{ng} \cdot \mathrm{h}^{-1}$, and $0.08 \mathrm{ng} \cdot \mathrm{h}^{-1}$ respectively) on the third day of collection (Day III).

Interaction between damage type and the time of collection was significant for all other compounds except LIN and B-CAR (Fig. 4). These were because greater amounts of GLV were released in the first day by scraped than by pierced wheat plants. That no interaction was observed for LIN and $\beta-C A R$ was not surprising as these terpenoids were not released in significant amounts by mechanically injured wheat plants (Fig. $3 \mathrm{~g}, \mathrm{~h}$ ).

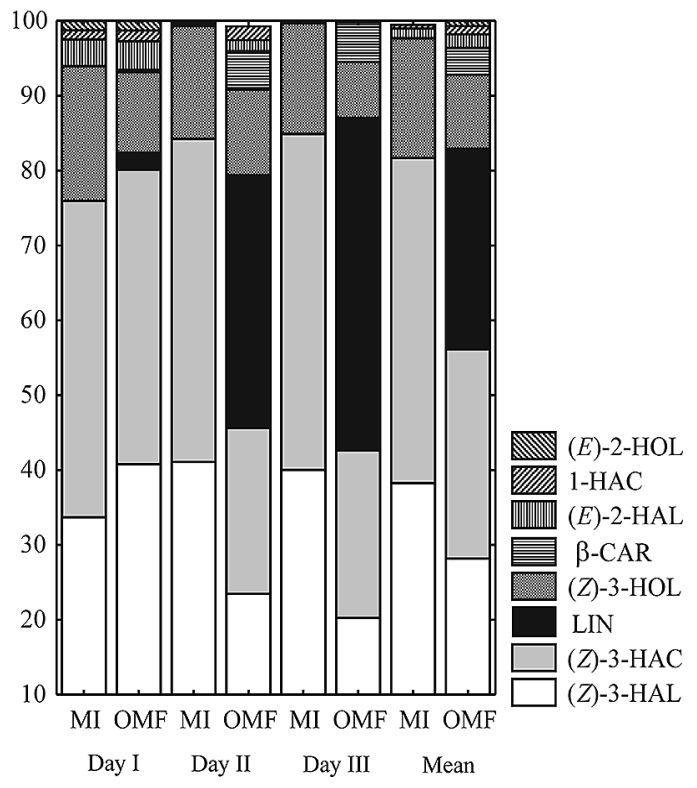

Fig. 5. Total amount of volatile organic compounds released by winter wheat cv. 'Tonacja' in consequence of $O$. melanopus feeding (OMF) and mechanical injury (MI) (means of scraped and pierced plants).

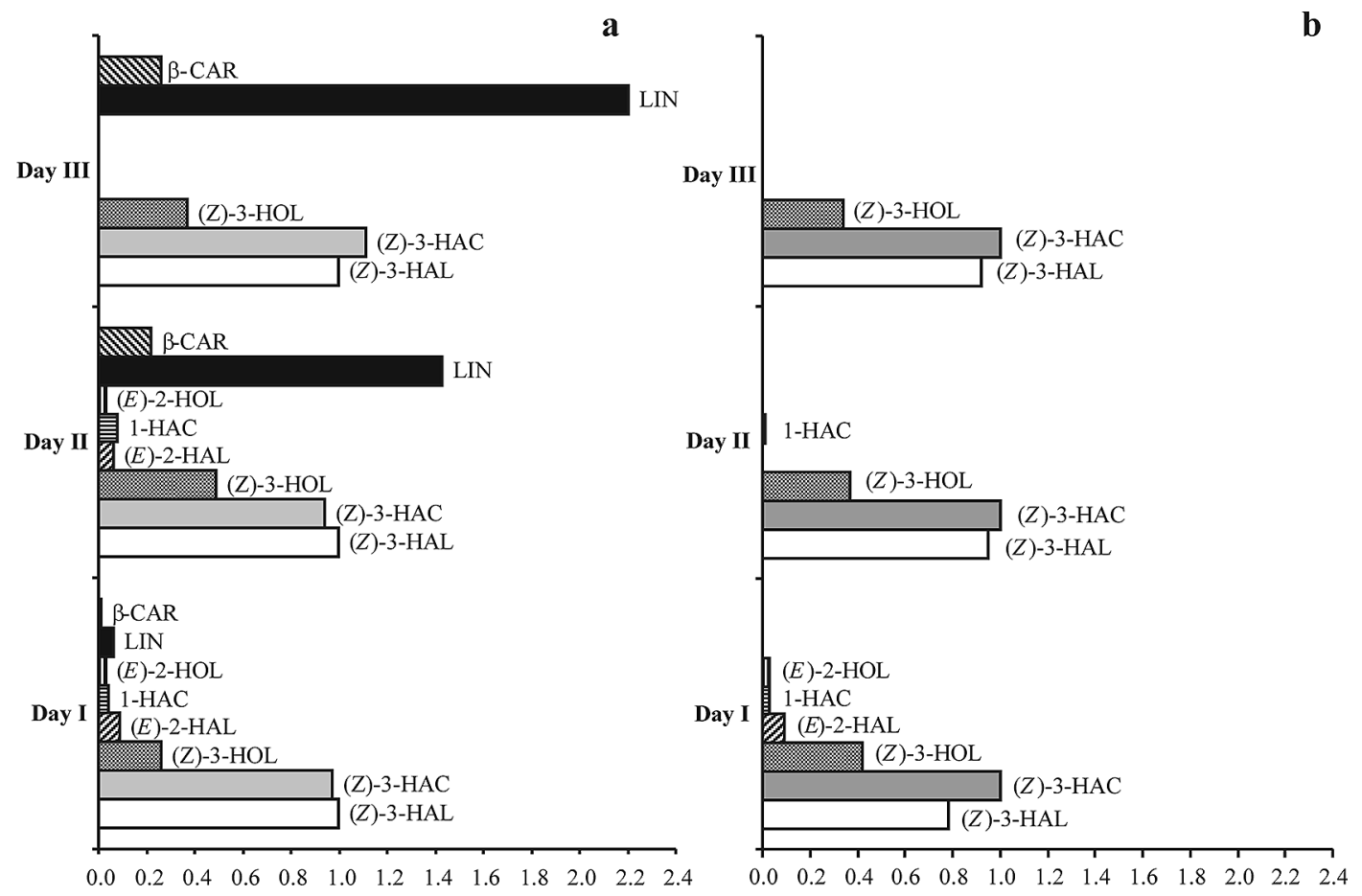

Fig. 6. VOC ratios of winter wheat cv. 'Tonacja'. - a. After O. melanopus feeding. - b. After mechanical injury. Ratio $=S_{\text {selected }} / S_{H A C}$, where $S_{\text {selected }}$ is the amount of a selected volatile and $S_{H A C}$ is the amount of (Z)-3-HAC; the latter was released the largest amount of the analysed compounds in consequence of both $\mathrm{O}$. melanopus feeding and mechanical injury. 
Table 2. Effect of synthetic (Z)-3-HAL, (Z)-3-HAC, and LIN volatiles (ng $\mathrm{min}^{-1}$ ) on adults of O. melanopus behavior.

\begin{tabular}{|c|c|c|c|c|c|c|c|c|}
\hline \multirow{2}{*}{$\begin{array}{l}\text { Name of } \\
\text { compound }\end{array}$} & \multirow[t]{2}{*}{ Days } & \multirow[t]{2}{*}{$\mathrm{ng} \cdot \mathrm{min}^{-1}$} & \multicolumn{2}{|c|}{ No. of females } & \multirow[b]{2}{*}{$\chi^{2}$} & \multicolumn{2}{|c|}{ No. of males } & \multirow[b]{2}{*}{$\chi^{2}$} \\
\hline & & & $+{ }^{\$}$ & $-{ }^{\$}$ & & $+{ }^{\$}$ & $-{ }^{\$}$ & \\
\hline \multirow[t]{4}{*}{ (Z)-3-HAL } & I & 6.8 & 26 & 4 & $14.7^{* \star *}(\mathrm{r})$ & 24 & 6 & $9.63^{* *}(r)$ \\
\hline & II & 1.3 & 23 & 7 & $7.5^{* *}(r)$ & 22 & 8 & $5.63^{*}(r)$ \\
\hline & III & 0.5 & 14 & 16 & $0.03 \mathrm{~ns}$ & 14 & 16 & $0.03 \mathrm{~ns}$ \\
\hline & control $^{£}$ & 0.5 & 24 & 6 & $9.63^{* *}(a)$ & 16 & 14 & $0.03 \mathrm{~ns}$ \\
\hline \multirow[t]{4}{*}{ (Z)-3-HAC } & I & 6.5 & 25 & 5 & $12.03^{* * *}(r)$ & 24 & 6 & $9.63^{* *}(r)$ \\
\hline & II & 1.2 & 22 & 8 & $5.63^{*}$ & 23 & 7 & $7.5^{* *}(r)$ \\
\hline & III & 0.5 & 16 & 14 & $0.03 \mathrm{~ns}$ & 14 & 16 & $0.03 \mathrm{~ns}$ \\
\hline & control $^{\varepsilon}$ & 0.5 & 22 & 8 & $5.63^{*}(a)$ & 14 & 16 & $0.03 \mathrm{~ns}$ \\
\hline \multirow[t]{4}{*}{ LIN } & I & 0.4 & 22 & 8 & $5.63^{*}(r)$ & 16 & 14 & $0.03 \mathrm{~ns}$ \\
\hline & II & 1.9 & 26 & 4 & $14.7^{\star \star \star}(r)$ & 25 & 5 & $12.03^{\star * *}(r)$ \\
\hline & & 1.1 & 23 & 7 & $7.5^{\star *}(r)$ & 24 & 6 & $9.63^{* *}(r)$ \\
\hline & control $^{\varepsilon}$ & 0.0 & 18 & 12 & $0.83 \mathrm{~ns}$ & 12 & 18 & $0.83 \mathrm{~ns}$ \\
\hline
\end{tabular}

Levels of significance: ${ }^{*}, p<0.05 ;{ }^{* *}, p<0.01 ;{ }^{* * *}, p<0.001$; ns, not significant

$r=$ repellent, $a=$ attractant

$\$=+$ : Y-tube arm with tested amount of the compound, volatile diluted in hexane emitted from filter paper; -: Y-tube arm only with hexane emitted from filter paper

$£=$ mean of three days

\subsubsection{Total amounts and relative composition of volatiles after foliar damage}

The control plants released very low amounts of volatiles (means of three days); LIN: $0.04 \mathrm{ng} \cdot \mathrm{h}^{-1}$, $\mathrm{F}(2 ; 15)=3.06 ;$ ß-CAR: $0.03 \mathrm{ng} \cdot \mathrm{h}^{-1}, \mathrm{~F}(2 ; 15)=$ $0.66 ;(E)-2-H A L: 0.06 \mathrm{ng} \cdot \mathrm{h}^{-1}, \mathrm{~F}(2 ; 15)=2.31$; (E)-2-HOL: $0.03 \mathrm{ng} \cdot \mathrm{h}^{-1}, \mathrm{~F}(2 ; 15)=1.41 ;(Z)-3$ HAC: $29.72 \mathrm{ng} \cdot \mathrm{h}^{-1}, \mathrm{~F}(2 ; 15)=0.29 ;(Z)-3-\mathrm{HAL}$ : $30.11 \mathrm{ng} \cdot \mathrm{h}^{-1}, \mathrm{~F}(2 ; 15)=0.54 ; 1-\mathrm{HAC}: 0.04 \mathrm{ng} \cdot \mathrm{h}^{-1}$, $\mathrm{F}(2 ; 15)=4.16 ;(Z)-3-\mathrm{HOL}: 10.84 \mathrm{ng} \cdot \mathrm{h}^{-1}, \mathrm{~F}(2 ; 15)$ $=0.68$ (Fig. 3).

Three volatile compounds produced in consequence of $O$. melanopus feeding, (Z)-3-HAC, (Z)-3-HAL, and LIN, were emitted in considerably greater amounts compared to the other volatiles, peaking at a mean over $80 \%$ of total volatiles released (Fig. 5). On average, plants released over 1.4-fold more (day II) and approximately 2.2-fold more (day III) LIN than (Z)-3HAL (Fig. 6a).

In contrast, undetected amounts of LIN and BCAR as a result of mechanical injury were observed (Fig. 6b). Two major volatile compounds produced by mechanically injured wheat plants ((Z)-3-HAC and (Z)-3-HAL) were emitted in considerably greater amounts than other compounds. Generally (Z)-3-HAC was the major component released by plants in consequence of mechanical injury (Fig. 6b). Of all identified volatiles, (Z)-3-HAC release was clearly highest across the collection days, peaking at a mean of $46.57 \mathrm{ng} \cdot \mathrm{h}^{-1}$ (mean of three days). Similar tendency was observed for (Z)-3-HAL, which reached $39.71 \mathrm{ng} \cdot \mathrm{h}^{-1}$ (mean of three days).

\subsection{Behaviour of $O$. melanopus in Y-tube experiment}

Only females were attracted to low concentrations $\left(0.5 \mathrm{ng} \cdot \mathrm{min}^{-1}\right)$ of $(Z)-3$-HAL and $(Z)-3$ HAC (Table 2). Surprisingly, male cereal leaf beetles did not show any preference and they were not attracted to low concentrations of GLV. Repellency (high concentration of tested compounds) was observed for both females and males to (Z)-3-HAL, (Z)-3-HAC, and LIN. The largest repellent effect was observed for (Z)-3-HAL (6.8 $\left.\mathrm{ng} \cdot \mathrm{min}^{-1}\right)$ and LIN (1.9 $\left.\mathrm{ng} \cdot \mathrm{min}^{-1}\right)$ (Table 2).

\section{Discussion}

It is well known that plants can produce secondary metabolites (Chamberlain et al. 2000) to increase their resistance against herbivores (Shiojiri \& Karban 2008). These compounds may be 
involved in plant defense against herbivores or pathogens (Wang \& Dorn 2003, Jiménez-Martinez et al. 2004, Thompson \& Goggin 2006).

In this study, we observed that different types of mechanical injuries (piercing, scraping) induced the release of greater amount of (Z)-3HAL, (E)-2-HAL, (Z)-3-HOL, (E)-2-HOL, (Z)$3-\mathrm{HAC}$, and 1-HAC in comparison to control plants. The increase of those compounds was quite distinct depending on injury type. Generally larger abundance of volatiles was observed for scraped leaves than for pierced ones. Hoballah and Turlings (2005) reported that generally any type of surface damage commonly causes plant leaves to release GLV. Also, Banchio et al. (2005) reported that Minthostachys mollis plants responded to mechanical damage by dramatically increasing the concentration of the two most abundant monoterpenes (menthone and pulegone) in their essential oil. Moreover, we observed larger amounts of semiochemicals in consequence of insect damage than either type of mechanical damage. This is in good agreement with Farag and Paré (2002) who demonstrated that tomato plants (Lycopersicon esculentum), in response to insect feeding, released both locally and systemically elevated levels of volatile organic compounds. GLV were released by both mechanically damaged and insect-attacked wheat plants. Also, Engelberth et al. (2004) demonstrated a specific function of GLV in priming the defenses of corn plants against herbivorous insects. In our experiments, LIN and B-CAR were not released by mechanically-injured wheat plants. This is in agreement with experiments by Röse et al. (1996, 1998), who demonstrated that systemically released compounds like linalool, known to be induced by caterpillar feeding damage, slightly increased by mechanical injury, and were not released in significant amounts from undamaged cotton plants. This integration can be apparent from the effects induced by host plants on insect physiology and behavior, including reproduction (Reddy \& Guerrero 2004).

We observed that feeding of insects induced the release of LIN and B-CAR more strongly in the 2 nd and $3^{\text {rd }}$ days after injury than in the 1 st day. Our results are in good agreement with Turlings et al. (1998), who found that emission of induced volatiles in plants infested by Spodop- tera and Ostrinia lasted throughout the 3 days. On day 2, on the other hand, the emissions of GLV were relatively low, which may have been due to the fact that most caterpillars were in the process of molting to the fourth instar and did not feed much.

Female cereal leaf beetles responded positively to low concentrations of GLV ((Z)-3-HAL, (Z)-3-HAC) emitted by control plants. However, higher concentrations of two GLV and LIN repelled both females and males. Bruce et al. (2005) noticed that for attraction or repellency additional factors are required, such as exposure to blends of compounds in the same ratios as those produced by plants.

The dramatic treatment effects observed encourage further investigation of the ecological role of these active substances in response to damage (Ninkovic et al. 2003). It would be of importance to investigate how these secondary metabolites can impact natural enemy and herbivores (Wang \& Dorn 2003). Manipulation of semiochemicals could also aid in the use of trap cropping to manage this insect (Piesik et al. 2008). An understanding of insect-plant interactions and chemical ecology is needed for the success of management practices relying on semiochemicals (Cook et al. 2007).

Acknowledgments. We thank David K. Weaver (Department of Land Resources and Environmental Sciences, Montana State University) for help in analytical methods.

\section{References}

Agrawal, A. A., Tuzun, S. \& Bent, E. 1999: Induced plant defenses against pathogens and herbivores. - APS Press, St. Paul, Minnesota. 390 pp.

Alvarez-Castellanos, P. P., Bishop, C. D. \& Pascual-Villalobos, M. J. 2001: Antifungal activity of the essential oil of flowerheads of garland chrysanthemum (Chrysanthemum coronarium) against agricultural pathogens. - Phytochemistry 57: 99-102.

Banchio, E., Zygadlo, J. \& Valladares, G. R. 2005: Effects of mechanical wounding on essential oil composition and emission of volatiles from Minthostachys mollis. - Journal of Chemical Ecology 31: 719-727.

Bayram, A., Doganlar, O., Can, F. \& Kornosor, S. 2004: The distribution and host plants of the cereal leaf beetle (Oulema melanopus (L.), Coleoptera: Chrysomelidae) in the East Mediterranean region of Turkey. Ziraat Fakultesi Dergisi, Mustafa Kemal Universitesi 9: 43-49. 
Buntin, G. D., Flanders, K. L., Slaughter, R. W. \& De Lamar, Z. D. 2004: Damage loss assessment and control of the cereal leaf beetle (Coleoptera: Chrysomelidae) in winter wheat. - Journal of Economic Entomology 97: 374-382.

Buttery, R. G., Xu, C.-J. \& Ling, L. C. 1985: Volatile components of wheat leaves (and stems): possible insect attractants. - Journal of Agricultural and Food Chemistry 33: 115-117.

Bruce, T. J. A., Wadhams, L. J. \& Woodcock, C. M. 2005: Insect host location: a volatile situation. - Trends in Plant Science 10: 269-274.

Cardoza, Y. J., Albron, H. T. \& Tumlinson, J. H. 2002: In vivo volatile emissions from peanut plants induced by simultaneous fungal infection and insect damage. Journal of Chemical Ecology 28: 161-174.

Cardoza, Y. J., Teal, P. E. A. \& Tumlinson, J. H. 2003: Effect of peanut plant fungal infection on oviposition preference by Spodoptera exigua and on host-searching behavior by Cotesia marginiventris. - Environmental Entomology 32: 970-976.

Chamberlain, K., Pickett, J. A. \& Woodcock, C. M. 2000: Plant signaling and induced defence in insect attack. - Molecular Plant Pathology 1: 67-72.

Cook, S. M., Khan, Z. R. \& Pickett, J. A. 2007: The use of push-pull strategies in integrated pest management. Annual Review of Entomology 52: 375-400.

De Moraes, C. M., Lewis, W. J., Paré, P. W., Alborn, H. T. \& Tumlinson, J. H. 1998: Herbivore-infested plants selectively attract parasitoids. — Nature 393: 570 573.

De Moraes, C. M., Mescher, M. C. \& Tumlinson, J. H. 2001: Caterpillar-induced nocturnal plant volatiles repel nonspecific females. - Nature 410: 577-580.

Dicke, M. \& Sabelis, M. W. 1988: How plants obtain predatory mites as bodyguards.

— Netherlands Journal of Zoology 38: 148-165.

Dimitrijevic, B., Jelic, M. \& Lomovic, S. 1999: The effect of mineral nutrition on the damage degree of spring wheat by Lema melanopus L. (Coleoptera: Chrysomelidae). - Acta Entomologica Serbica 4: 49-55.

Engelberth, J., Alborn, H. T., Schmelz, E. A. \& Tumlinson, J. H. 2004: Airborne signals prime plants against insect herbivore attack. — Plant Biology 101: 17811785 .

Farag, M. A. \& Paré, P. W. 2002: C6 - green leaf volatiles trigger local and systemic VOC emission in tomato. Phytochemistry 61: 545-554.

Hoballah, M. E. \& Turlings, T. C. J. 2005: The role of fresh versus old leaf damage in the attraction of parasitic wasps to herbivore-induced maize volatiles. - Journal of Chemical Ecology 31: 2003-2018.

Jiménez-Martínez, E. S., Bosque-Pérez, N. A., Berger, P. H., Zemetra, R. S., Ding, H. \& Eigenbrode, S. D. 2004: Volatile cues influence the response of Rhopalosiphum padi (Homoptera: Aphididae) to Barley yellow dwarf virus-infected transgenic and untransformed wheat. — Environmental Entomology 33: 12071216.

Karban, R. 1985: Resistance against spider mites in cotton induced by mechanical abrasion. — Entomologia Experimentalis et Applicata 37: 137-141.

Karban, R. \& Baldwin, I. T. 1997: Induced responses to herbivory. - Univ. Press Chicago. 320 pp.

Kessler A. \& Baldwin, I. T. 2001: Defensive function of herbivore-induced plant volatile emissions in nature. - Science 291: 2141-2144.

McCall, P. J., Turlings, T. C. J., Lewis, W. J. \& Tumlinson, J. H. 1993: Role of plant volatiles in host location by the specialist parasitoid Microplitis croceipes Cresson (Braconidae: Hymenoptera). — Journal of Insects Behavior 6: 625-639.

Meindl, P., Kromp, B., Bartl, B. \& Ioannidou, E. 2001: Arthropod natural enemies of the cereal leaf beetle (Oulema melanopus L.) in organic winter wheat fields in Vienna, Eastern Austria. - Bulletin OILB/SROP 24:79-86.

Ninkovic, V., Ahmed, E., Glinwood, R. \& Pettersson, J. 2003: Effects of two types of semiochemical on population development of the bird cherry oat aphid Rhopalosiphum padi in a barley crop. - Agricultural and Forest Entomology 5: 27-33.

Olfert, O., Weiss, R. M., Woods, S., Philip, H. \& Dosdall, L. 2004: Potential distribution and relative abundance of an invasive cereal crop pest, Oulema melanopus (Coleoptera: Chrysomelidae), in Canada. — Canadian Entomologist 136: 277-287.

Piesik, D., Wenda-Piesik, A., Weaver, D. K. \& Morrill, W. L. 2007: Influence of Fusarium crown rot disease on semiochemical production by wheat plants. - Journal of Phytopathology 155: 488-496.

Piesik, D., Weaver, D. K., Runyon, J.B., Buteler, M., Peck, G. E. \& Morrill, W. L. 2008: Behavioural responses of wheat stem sawflies to wheat volatiles. - Agricultural and Forest Entomology 10: 245-253.

Popov, C., Malschi, D., Vilau, F. \& Stoica, V. 2005: Occurrence and damage of cereal leaf beetle (Oulema melanopus L.). Insect pest management of Lema melanopa in Romania. - Romanian Agricultural Research 22: 47-51.

Rasmann, S., Köllner, T. G. \& Degenhardt, J. 2005: Recruitment of entomopathogenic nematodes by insectdamaged maize roots. — Nature 434: 732-737.

Reddy, G. V. P. \& Guerrero, A. 2004: Interactions of insect pheromones and plant semiochemicals. - Trends in Plant Science 9: 253-261.

Röse, U. S. R., Manukian, A., Heath, R. R. \& Tumlinson, J. H. 1996: Volatile semiochemicals released from undamaged cotton leaves: A systemic response of living plants to caterpillar damage. - Plant Physiology 111: 487-495.

Röse, U. S. R., Lewis, J. W. \& Tumlinson, J. H. 1998: Specificity of systemically released cotton volatiles as attractants for specialist and generalist parasitic wasps. — Journal of Chemical Ecology 24: 303-319.

Shiojiri, K. \& Karban, R. 2008. Vascular systemic induced resistance for Artemisia cana and volatile communication for Artemisia douglasiana. — The American Midland Naturalist 159: 468-477. 
Sokal, R. R. \& Rohlf, F. J. 1995: Biometry: The Principles and Practice of Statistics in Biological Research. Freeman W.H. and Co., New York. 887 pp.

Sokolov, I. M. 1999: The effect of damage by larvae of the cereal leaf beetle Oulema melanopus (L.) (Coleoptera, Chrysomelidae) on the yield of winter wheat ears. Entomologicheskoe Obozrenie 78: 307-315.

Thaler, J. S. 1999: Jasmonate-inducible plant defences cause increased parasitism of herbivores. - Nature 399: 686-688.

Thaler, J. S., Karban, R., Ullman, D. E., Boege, K., Bostock, R. M. 2002: Cross-talk between jasmonate and salicylate plant defense pathways: effects on several plant parasites. - Oecologia 131: 227-235.

Thompson, G. A. \& Goggin, F. L 2006. Transcriptomics and functional genomics of plant defence induction by phloem-feeding insects. - Journal of Experimental Botany 57: 755-766.

Turlings, T. C. J., Tumlinson, J. H. \& Lewis, W. J. 1990: Exploitation of herbivore-induced plant odors by hostseeking parasitic wasps. - Science 250: 1251-1253.

Turlings, T. C. J., Bernasconi, M., Bertossa, R., Bigler, F., Caloz, G. \& Dorn, S. 1998: The induction of volatile emissions in maize by three herbivore species with different feeding habits: Possible consequences for their natural enemies. - Biological Control 11: 122-129.

Vikram, A., Hamzehzarghani, H. \& Kushalappa, A. C. 2005: Volatile metabolites from the headspace of onion bulbs inoculated with postharvest pathogens as a tool for disease discrimination. - Canadian Journal of Plant Pathology 27: 194-203.

Walczak, F. 2005a: Determination of developmental periods of leaf beetle (Oulema spp.) for short-term forecasting. - Journal of Plant Protection Research 45: $145-153$.

Walczak, F. 2005b: Studies on leaf beetles (Oulema spp.) development for short-term forecasting - evaluation of effect of temperature and humidity on duration of egg incubation. - Journal of Plant Protection Research 45: 135-143.

Wang, Q. H. \& Dorn, S. 2003: Selection on olfactory response to semiochemicals from a plant-host complex in a parasitic wasp. - Heredity 91: 430-435.

Zadoks, J. C., Chang, T. T. \& Konzak, C. F. 1974: A decimal code for the growth stages of cereals. - Weed Research 14: 415-421. 